\title{
Conventional Total Station Versus Digital Photogrammetry in Land Development Applications
}

\author{
Yaguba Jalloh*, Anuar Ahmad, Zulkarnaini Mat Amin and Kuyoro Sasaki*
}

Faculty of Engineering, Department of Earth Resources Engineering, Kyushu University, Fukuoka, Japan

\begin{abstract}
In land development, the need for up to date planimetric plans is emphasised. Numerous techniques can be used to produce these plans such as traditional photogrammetry, satellite photogrammetry and terrestrial surveying using total station or Global Positioning System (GPS) techniques. However, for the purpose of this paper, GPS and total station are used together with photogrammetric techniques. GPS was used to establish ground control points for aerial triangulation in photogrammetry. Some selected portions within the campus of Universiti Teknologi Malaysia (UTM) are chosen to carry out this integration mapping [1]. Field surveying technique using total station is always adopted as a traditional method for planimetric plan production and mapping of urban and rural areas. Both the conventional surveying i.e., Total station and photogrammetry could be used for surveying purposes but the accuracy and techniques of each method differs from one another, hence in this project, both techniques are looked at in order to compare and draw some inferences. The main objectives will be to produce planimetric plan of the study area using conventional surveying technique (i.e., total station) and photogrammetric method to perform analysis of the two surveying methods.
\end{abstract}

Keywords: Digital photogrammetry; Engineering; Photographs; Engineering plan

\section{Introduction}

Conventional surveying mainly comprises of the modern methods of automation survey such as; electronic measurement instrumentation, computer hardware and software [2]. These modern components have changed and drastically improve survey practices both in terms of data acquisition, processing as well as the presentation of the final survey result. The fundamental principle used by photogrammetry is triangulation, by taking photographs from at least two different locations; so-called "lines of sight" can be developed from each camera to points on the object. These lines of sight are sometimes called rays owing to their optical nature and are mathematically intersected to produce the 3-dimensional coordinates of the points of interest. Triangulation is also the principle used by theodolites/total station for coordinate measurement. It is the way our two eyes work together to gauge distance (called depth perception). To obtain the high accuracy, reliability and automation the system is capable of; the photographs must be of the highest quality. It is also the principle used by photogrammetry and theodolites/ total station to produce point measurements. By mathematically intersecting converging lines in space, the precise location of the point can be determined. However, unlike theodolites or total station, photogrammetry can measure multiple points at a time with virtually no limit on the number of simultaneously triangulated points. In the case of theodolites or total station, two angles are measured to generate a line from each instrument, but in photogrammetry the two dimensional ( $\mathrm{x}$, y) location of the target on the image are measured to produce this line. The main aim of this paper is to perform a comparative analysis of the two surveying methods, in terms of quantitative and qualitative $[3,4]$

\section{Materials and Methods}

It gives the outline and steps involved in photogrammetric and engineering plan production. The steps include data collection, input, processing and output procedures (Figure 1).

Appropriate points (about eight points) were identified in the photographs and field survey was done to establish the corresponding control points on the ground using rapid static GPS observation. The observations were carried out for duration of about 15 minutes at each point using a Trimble 4800 GPS receiver. These GCPs were input into to the software and processed, during point measurements. Traversing, levelling and detailing were done within the selected area. Software such as; civil design survey (CDS) and AutoCAD were used to process the data. Field surveying techniques using total station (Topcon GTS239N$62)$ is done [5-7].

\section{Results and Analyses}

Results and analyses of the study are very important for the final evaluation of the study from which necessary conclusions and recommendation are made. The final results of the detailed plans of both techniques are presented and discussed for comparative analyses.

\section{Photogrammetric plan}

Figures 2 and 3 show the digitized stereo- model, photogrammetric plan and Engineering plan of the project.

\section{Engineering plan}

The arrows indicate the common places of the two plans. At each point, arrows of the same colour indicate common points of the two plans.

\section{Quantitative analysis}

The quantitative analysis is the process of assigning numbers to a

*Corresponding authors: Yaguba Jalloh, Faculty of Engineering, Department of Earth Resources Engineering, Kyushu University, Fukuoka, Japan, Tel: +23276503624; E-mail: yjalloh2003@yahoo.com

Kuyoro Sasaki, Faculty of Engineering, Department of Earth Resources Engineering, Kyushu University, Fukuoka, Japan, Tel: +81928023326; E-mail: krsasaki@mine.kyushu-u.ac.jp

Received December 23, 2016; Accepted December 29, 2016; Published January 21, 2017

Citation: Jalloh Y, Ahmad A, Amin ZM, Sasaki K (2017) Conventional Total Station Versus Digital Photogrammetry in Land Development Applications. J Environ Anal Toxicol 7: 430. doi: 10.4172/2161-0525.1000430

Copyright: ( 2017 Jalloh Y, et al. This is an open-access article distributed under the terms of the Creative Commons Attribution License, which permits unrestricted use, distribution, and reproduction in any medium, provided the original author and source are credited. 
Citation: Jalloh Y, Ahmad A, Amin ZM, Sasaki K (2017) Conventional Total Station Versus Digital Photogrammetry in Land Development Applications. J Environ Anal Toxicol 7: 430. doi: 10.4172/2161-0525.1000430

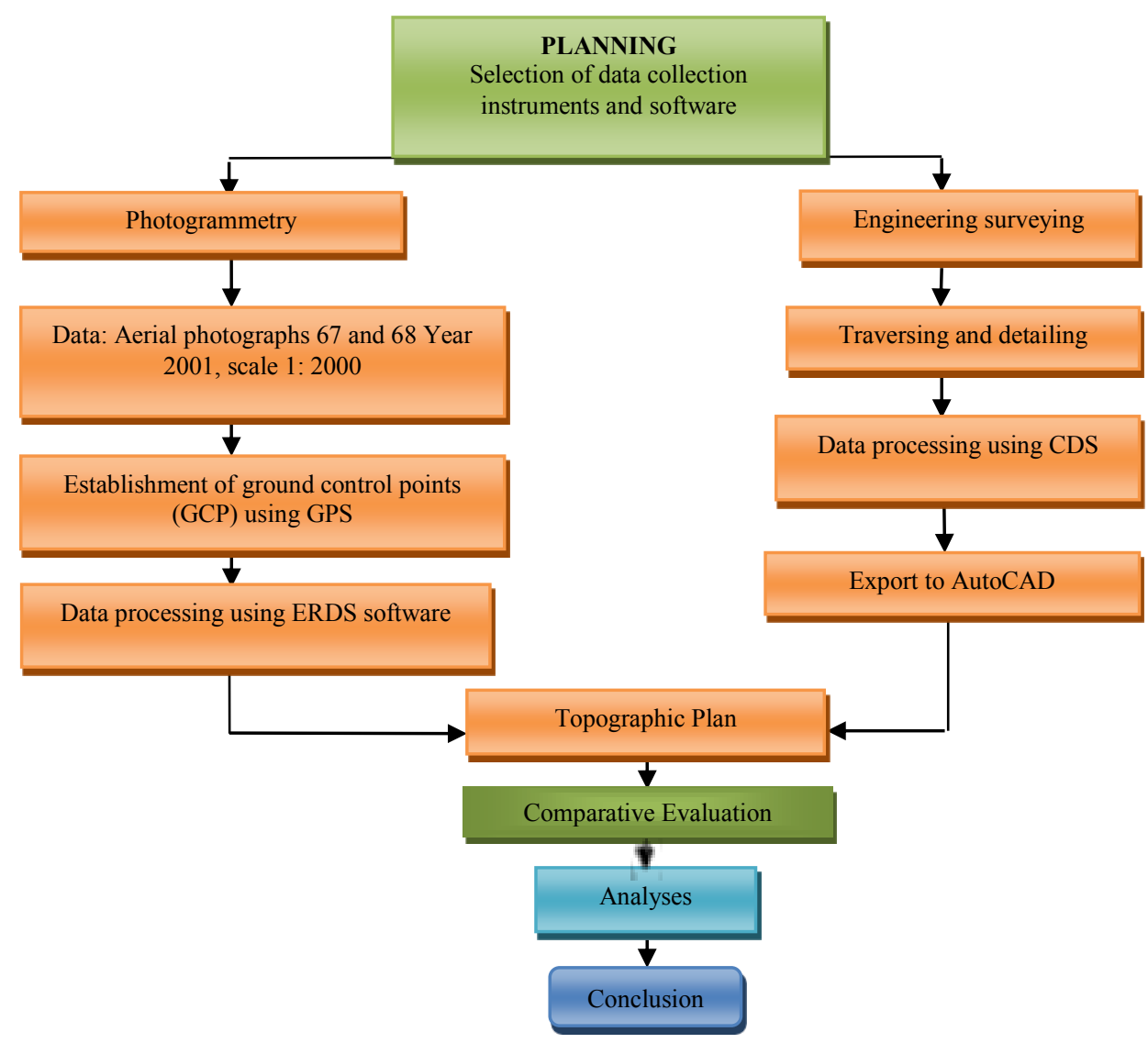

Figure 1: Flow chart of the research methodology.
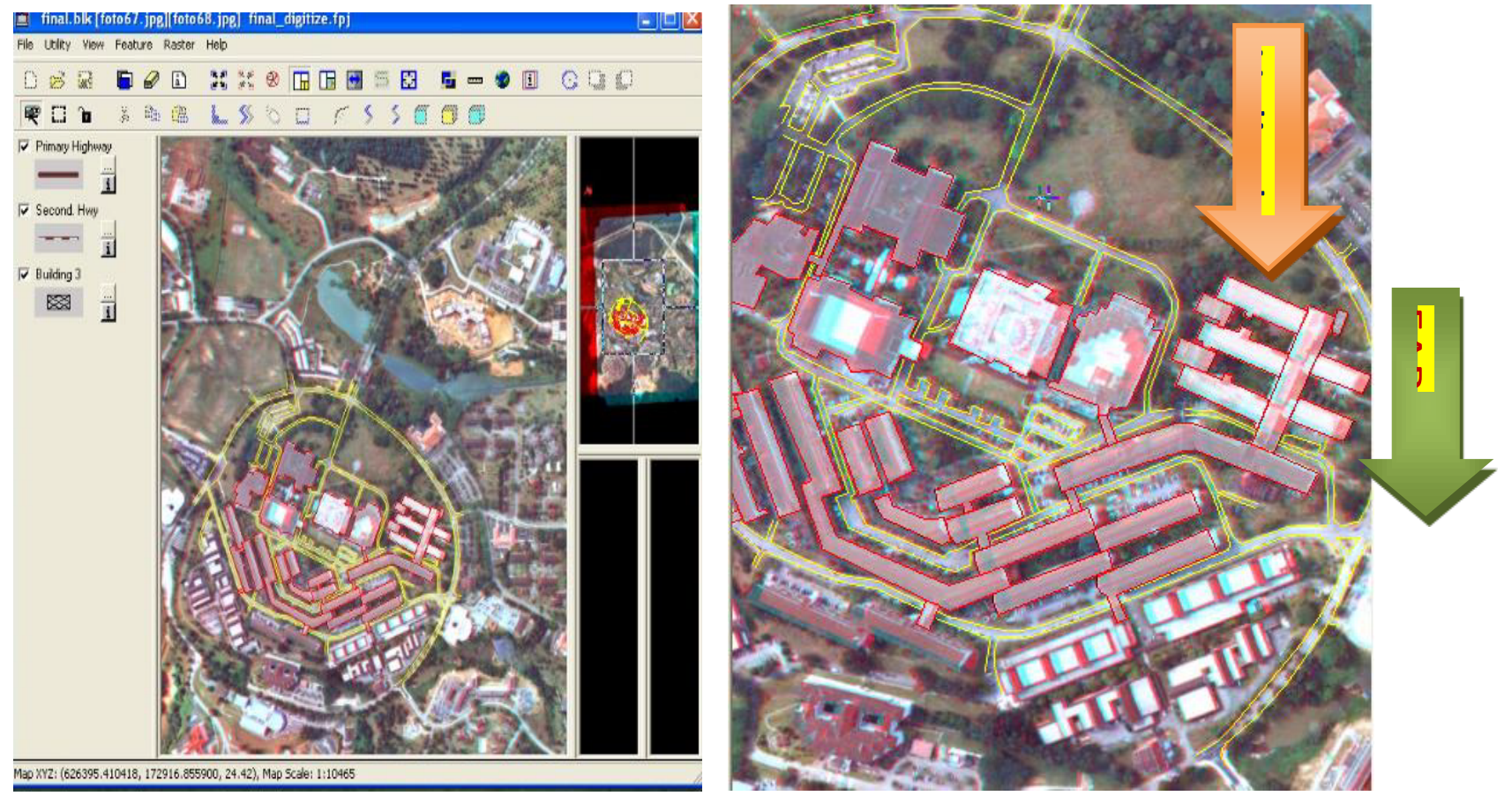

Figure 2: Digitized stereo-model and photogrammetric plan. 
Citation: Jalloh Y, Ahmad A, Amin ZM, Sasaki K (2017) Conventional Total Station Versus Digital Photogrammetry in Land Development Applications. J Environ Anal Toxicol 7: 430. doi: 10.4172/2161-0525.1000430
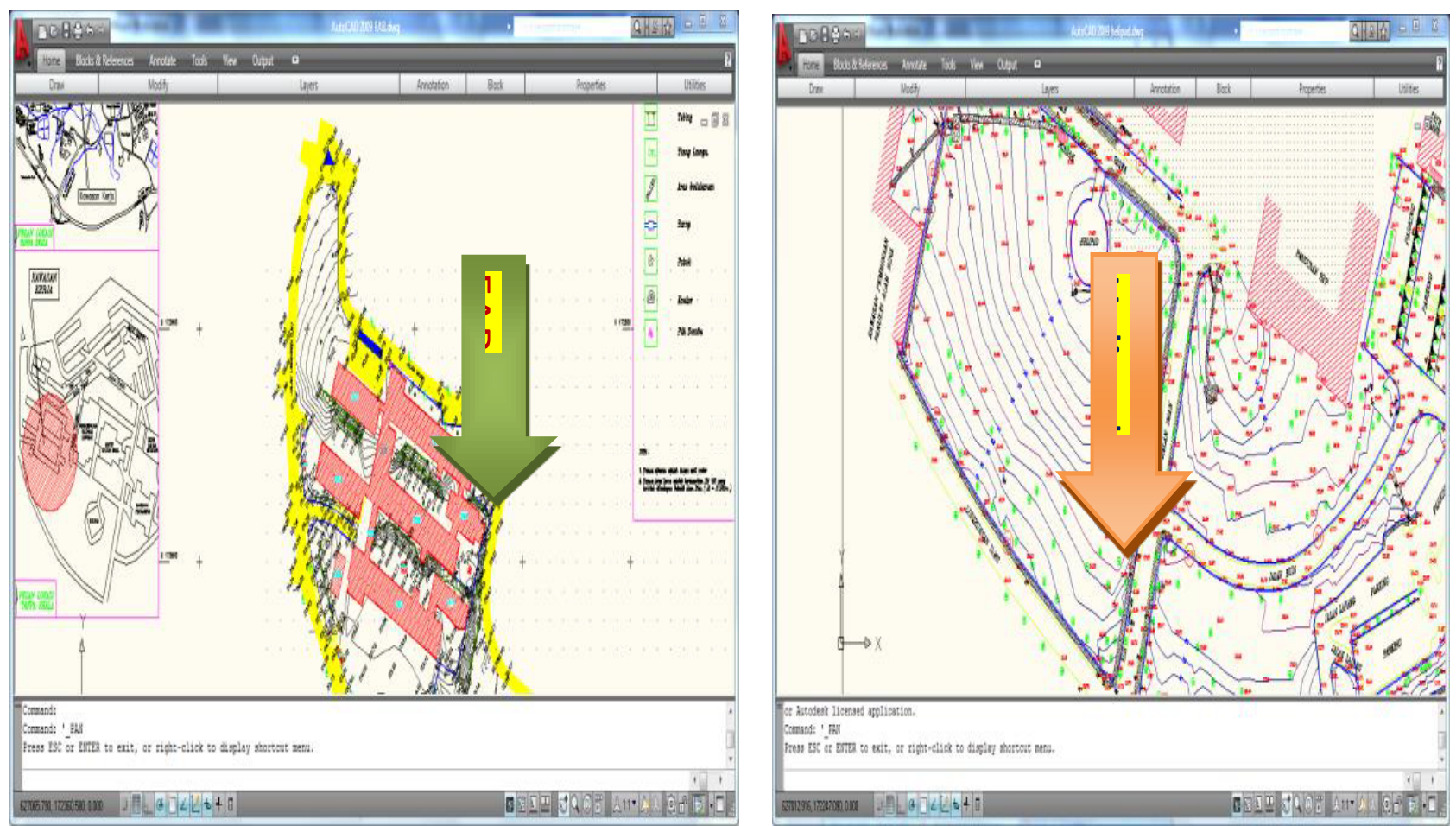

Figure 3: Engineering plan of FAB and the Helipad of UTM campus respectively.

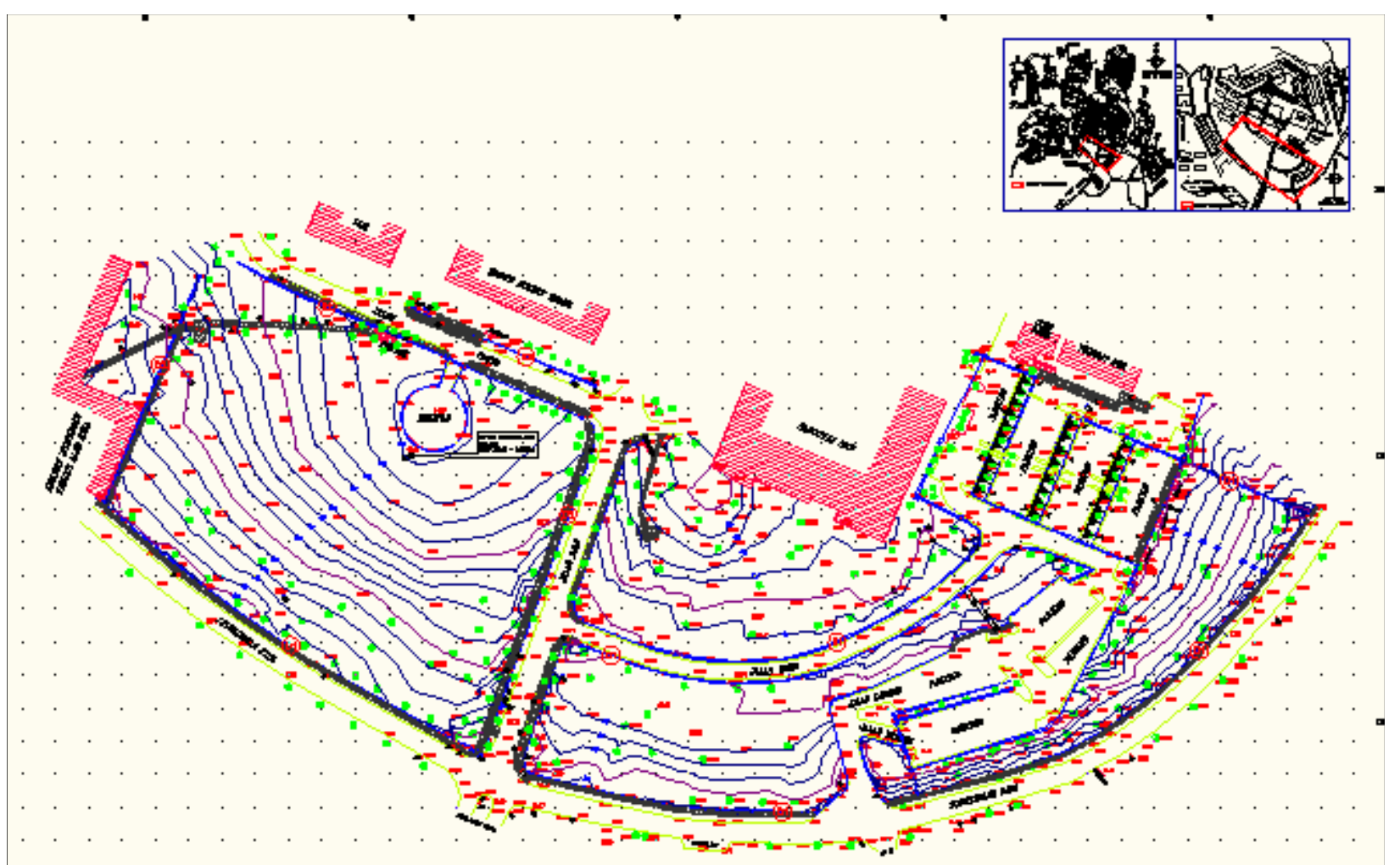

Figure 4: Example of the helipad area in UTM campus for qualitative analyse. 
Citation: Jalloh Y, Ahmad A, Amin ZM, Sasaki K (2017) Conventional Total Station Versus Digital Photogrammetry in Land Development Applications. J Environ Anal Toxicol 7: 430. doi: 10.4172/2161-0525.1000430

Page 4 of 5

phenomenon according to a given set of rules. This form of analysis is numerical and may be characterized by computational and calculative procedures. The orthophoto generated was analysed by comparing the CPs with total station coordinates.

Comparison between GCPs from total station and Erdas: Mathematically, the root mean square error (RMSE) is a statistical measure of the magnitude of a varying quantity. It is a kind of a generalized standard deviation and is useful when differences between subgroups or relationships between variables are looked at. The name comes from the fact that it is the square root of the mean of the values. In order to achieve the objective of this analysis, a selection of a random sample of points was done. Ground coordinates were obtained during aerial triangulation process from stereo-model using Erdas and the values obtained were compared with those obtained from conventional surveying using total station to determine the accuracy in terms of both plannimetry and height [8].

The digitizing process should be carefully done so as to obtain the "real" or a more accurate X, Y, Z coordinate for the point on the ground. Errors may be minimized during digitizing by using the anaglyph glasses and the digitizer must scroll upwards and downwards using the mouse until the two separate cursors coincide then the point may be picked from the ERDAS stereo model. Otherwise, without this procedure the user may obtain fairly accurate values for the spatial quantities of the features i.e., $\mathrm{X}$ and $\mathrm{Y}$ but the $\mathrm{Z}$ coordinate will either be below or above the ground surface causing significant errors in the quantitative analysis. Table 1 shows the results obtained from the two processes $[9,10]$.
Calculation of RMSE of $\mathrm{X}, \mathrm{Y}$ and $\mathrm{Z}$ values was done and the differences in plannimetry and height which are derived by differencing the two sets of coordinates that are obtained from conventional ground survey using total station and stereo-model from Erdas software. From the results obtained, it shows that the differences between the two sets of coordinates are not great which ranges from a few millimetres to centimetres level.

\section{Qualitative analyses}

The qualitative analysis can be described as an in depth analysis which considers or narrows down the project to a small section of the sample data to investigate and compare conformity of the two sets of data. The qualitative analysis carried out in this research is a comparison of a small sample area in the overall case study area from aerial triangulation. The area considered for the qualitative analysis is within the vicinity of the helipad in UTM campus, as represented in Figure 4.

The digitized version of the structures and building in the area from the stereo model in Erdas software are exported to ArcGIS and superimposed with the engineering plan (Figure 5).

The analysis carried out in this study is subject to the area of case study (within UTM campus) and the sample data considered for this project. Hence, whereas the results obtained in the research and presented herein are conclusive for this project, they may not necessarily be subjective to another area of study. Having said that, the researcher feels confident enough to conclude that the research carried out was a complete success and the analysis carried out holds proof for

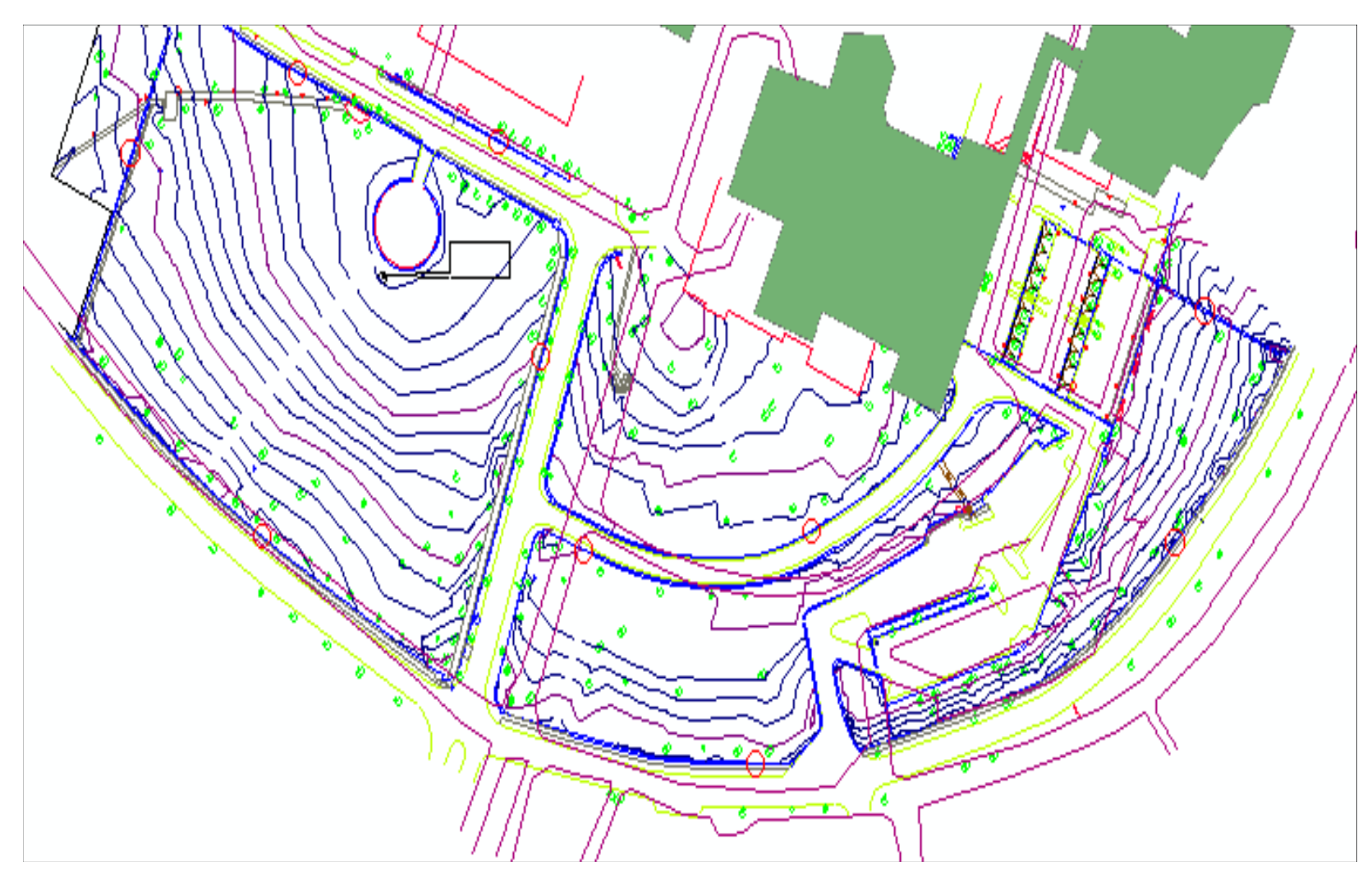

Figure 5: Example of the superimposed results of ERDAS digitizing with direct ground surveying results in ArcGIS. 
Citation: Jalloh Y, Ahmad A, Amin ZM, Sasaki K (2017) Conventional Total Station Versus Digital Photogrammetry in Land Development Applications. J Environ Anal Toxicol 7: 430. doi: 10.4172/2161-0525.1000430

Page 5 of 5

\begin{tabular}{|c|c|c|c|c|c|c|c|c|c|}
\hline \multirow[b]{2}{*}{ Point No. } & \multicolumn{3}{|c|}{$\begin{array}{l}\text { Ground coordination from conventional survey using total } \\
\text { station }\end{array}$} & \multicolumn{3}{|c|}{$\begin{array}{l}\text { Ground coordinate from Stereo-Model usong } \\
\text { Erdas }\end{array}$} & \multicolumn{3}{|c|}{ Differences (?i) } \\
\hline & $X(m)$ & $\mathrm{Y}(\mathrm{m})$ & $Z(m)$ & $X(m)$ & $Y(m)$ & $Z(m)$ & ?X (m) & ?Y (m) & $? Z(m)$ \\
\hline 1 & 626707.872 & 172593.33 & 31.28 & 626707.718 & 172527.3 & 31.04 & 0.154 & 0.046 & 0.24 \\
\hline 2 & 626674.17 & 172573.83 & 28.08 & 626674.067 & 172573.3 & 28.76 & 0.103 & 0.563 & -0.68 \\
\hline 3 & 626679.986 & 172596.15 & 28.2 & 626679.591 & 172596.6 & 28.77 & 0.395 & -0.469 & -0.57 \\
\hline 4 & 626726.824 & 172659.52 & 27.83 & 626726.138 & 172659.3 & 27.92 & 0.686 & 0.213 & -0.09 \\
\hline 5 & 626723.778 & 172527.86 & 29.93 & 626723.304 & 172527.1 & 29.73 & 0.474 & 0.782 & 0.2 \\
\hline 6 & 626776.465 & 172582.92 & 31.56 & 626776.401 & 172582.2 & 31.13 & 0.064 & 0.709 & 0.43 \\
\hline 7 & 626895.006 & 172376.13 & 33.96 & 626913.437 & 172368.5 & 33.62 & -0.431 & -0.376 & 0.34 \\
\hline 8 & 626923.558 & 172364.06 & 34.22 & 626923.826 & 172364.7 & 33.64 & -0.268 & -0.68 & 0.58 \\
\hline 9 & 626983.785 & 172338.97 & 33.78 & 626983.189 & 172338.1 & 33.29 & 0.596 & 0.83 & 0.49 \\
\hline 10 & 626983.363 & 172324.88 & 32.96 & 626983.427 & 172324.1 & 32.21 & -0.064 & 0.772 & 0.75 \\
\hline 11 & 626895.749 & 172320.05 & 34.19 & 626895.144 & 172320.4 & 33.95 & 0.605 & -0.343 & 0.24 \\
\hline 12 & 626917.144 & 172209.91 & 18.85 & 626917.309 & 172209.8 & 18.18 & -0.165 & 0.065 & 0.67 \\
\hline 13 & 626792.478 & 172298.63 & 20.35 & 626792.127 & 172298 & 20.23 & 0.351 & 0.599 & 0.12 \\
\hline RMSE= & 117.967 & 147.93 & 5.045 & 119.333 & 143.689 & 4.986 & 0.359 & 0.54 & 0.436 \\
\hline
\end{tabular}

Table 1: Example of ground coordinates from Total station and ground coordinates from Erdas software.

the above statement [11].

\section{Conclusion}

The application, ability and capability of photogrammetry and engineering surveys and some of their associated software have been studied and understood. Qualitatively the two sets of numerical results obtained from the two methods were compared based on plannimetry and height. From the results obtained, it shows that the differences between the two sets of coordinates (X, Y and $\mathrm{Z}$ ) are not great which ranges from a few millimetres $(0.002 \mathrm{~mm})$ to centimetre level in plannimetry, from which it can be deduced that spatial displacement or plannimetry ( $\mathrm{X}$ and $\mathrm{Y}$ coordinates) of both conventional survey and check points from stereo-model are highly correlated which shows that both methods can be used to produce plans for land development purposes. Whereas the results obtained from other areas or data may be similar quite unlikely they would be completely numerically similar if a different methodology is followed with different software. Hence, the results and accuracy of this research is subject to the methodology followed by the researcher irrespective of its similarity with others.

\section{References}

1. Anuar A (2006) Digital Photogrammetry: An Experience of Processing Aerial Photograph of UTM Acquired using Digital Camera. $6^{\text {th }}$ International Conference
Asia GIS, 9-10 march 2006, Universiti Teknologi Malaysia, Malaysia.

2. Abduldadir A, Beckay MA (2008) Accuracy assessment of orthophoto base on various digital photogrammetric software.

3. De A (2007) Plane Surveying. S Chand \& Company Ltd., Ram Nagar, New Delhi, India.

4. Doyle F (1964) The historical development of analytical photogrammetry. Photogrammetric Engineering 30: 259-265.

5. Gay P, Woodward W (2004) Map projection and coordinates system. GIS Lounge.

6. History of Photogrammetry (2008) Center for photogrammetric training.

7. Jongchool CL, Taeho R. Application to Levelling using Total Station. Korea.

8. Control and Topographic Surveying. Engineering and Design. US Army Corps of Engineers. EM 1110-1-1005.

9. Konecny G (1986) The International Society for Photogrammetry and Remote Sensing, Keynote Address. Photogrammetric Engineering and Remote Sensing 51: 919-933.

10. Murai S, Otani $\mathrm{H}$, Ito $\mathrm{T}$ (2004) Digital photogrammetric system using tota station with the scanning function. Processing and Visualization using HighResolution Imagery, Pitsanulok, Thailand.

11. Abdel-Maguid RH, El-Manadily YS, El-Shazly AH (2005) A Rapid and CostEffective Technique for Planimetric Mapping of Small Villages in Developing Countries. Egypt. 